\title{
Distribution of soil corrosion grade in Southern Hebei Province
}

\author{
Jinxing $\mathrm{Yu}^{1}$, Xiangnan $\mathrm{Niu}^{1}$, Haiping $\mathrm{Hou}^{1}$, Kai $\mathrm{Che}^{1}$, Yike $\mathrm{Wei}^{2,{ }^{*}}$, and Ning $\mathrm{Yu}^{2}$ \\ ${ }^{1}$ Electric Power Research Institute of State Grid Hebei Electric Power Co., Ltd, Shijiazhuang, China \\ ${ }^{2}$ North China Electric Power University (Baoding), Hebei, China
}

\begin{abstract}
Transmission towers and substations are used in a variety of natural environments, coupled with the interference of the surrounding production and life, facing the test of soil corrosion. Based on the experimental data of 72 soil samples from five cities in Southern Hebei Province, the soil resistivity, soil $\mathrm{pH}$ value and soil moisture content were investigated, and the soil corrosion grade and soil corrosion grade distribution map were obtained. It provides a reference for the collection of soil corrosivity data in power transmission and transformation projects.
\end{abstract}

Keywords: Soil erosion; Soil resistivity; Regional distribution; Hebei province; Soil $\mathrm{pH}$.

\section{Introduction}

With the rapid development of China's economy, the scale of power construction has increased sharply. As an important part of power grid operation, the service safety of transmission towers and substations has attracted more and more attention. The above equipment is used in a variety of natural environments, coupled with the interference of the surrounding production and life, it is very likely that the materials will be damaged and failed in advance due to soil corrosion, which will affect the safe and efficient operation of the key equipment of power transmission and transformation. Hebei Southern Power Grid (including Shijiazhuang, Baoding, Cangzhou, Hengshui, Xingtai and Handan) covers a complex environment with different soil corrosion risks. Therefore, it is necessary to collect soil corrosivity data for power transmission and transformation project.

\section{Experiment}

In this study, 72 stations in five cities of Southern Hebei Province were sampled by the principle of on-site sampling packaging and centralized measurement in laboratory. The soil resistivity was measured by FUZRR FR3010E resistivity meter. Then, digging out a pit with a depth of about $60 \mathrm{~cm}$ and diameter of $40 \mathrm{~cm}$ at the collection point, and sampled $1 \mathrm{~kg}$.

Take about $20 \mathrm{~g}$ of sample soil, crush it, quickly put it into a large aluminium box with known accurate mass $\mathrm{M}_{0}$, cover it tightly, wipe the surface of the aluminium box clean, and weigh it to get the initial mass $\mathrm{M}_{1}$. Remove the lid of the box, put it under the box, and bake

* Corresponding author: wuzhenkee@foxmail.com 
it in the oven preheated to $105 \pm 2{ }^{\circ} \mathrm{C}$ for $12 \mathrm{~h}$. Take it out, cover it, cool it to room temperature in a dryer (about $30 \mathrm{~min}$ ), and weigh it immediately to get $\mathrm{m}_{2}$ [1]. The soil moisture content can be obtained by Formula 1 .

$$
\text { A , } \%=\frac{m_{1}-m_{2}}{m_{1}-m_{0}} \times 100
$$

Take appropriate amount of soil samples, spread them evenly, air dry at room temperature for 24 hours, grind them and pass through a sieve with a diameter of $1 \mathrm{~mm}$. Take $10 \mathrm{~g}$ of airdried soil sample after sieving, put it into a $50 \mathrm{ml}$ beaker, add $25 \mathrm{ml}$ of deionized water, stir for 1 minute to make the soil particles fully disperse, and then use a $\mathrm{pH}$ meter to determine after standing for 30 minutes [2].

The physical and chemical properties of soil samples were sorted out, and the degree of soil corrosion was graded by using three kinds of data. The soil corrosion evaluation system of three index method is shown in Figure 1. According to the results, the soil is divided into five grades, and the soil corrosivity is gradually strengthened.

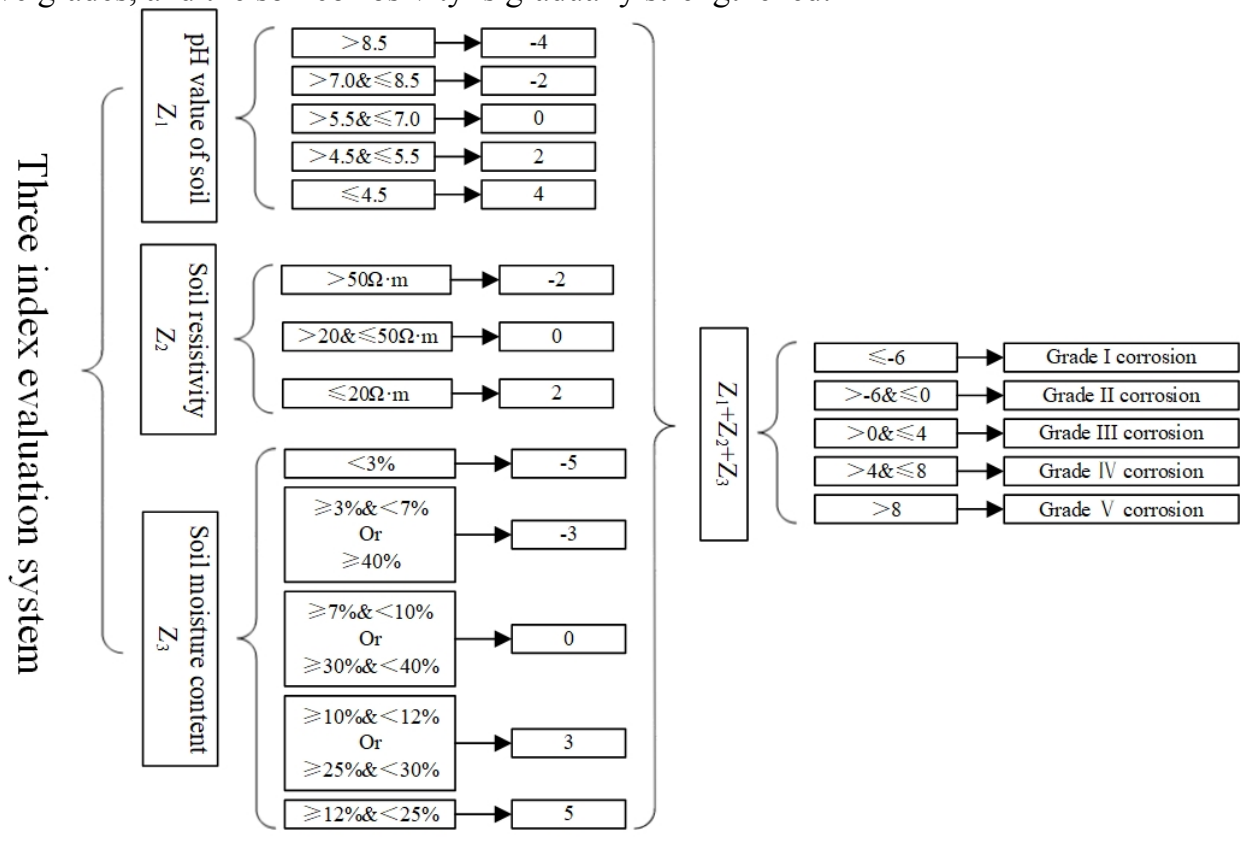

Fig. 1. Evaluation block diagram of three index method.

\section{Result}

\subsection{Soil moisture content}

The moisture content of soil is an important factor affecting the corrosion of metal materials.[3] When the moisture content is very high or very low, the corrosion rate is the lowest. The corrosion rate of metals increases first and then decreases with the increase of water content. When the soil water content is about $20 \%$, the corrosion rate is the highest. [47] In addition, the size of soil moisture also has an impact on soil resistivity. [8-9]

The moisture content of soil samples at each station is shown in Figure 2. It can be seen that the moisture content of most stations is concentrated in the range of $12 \%-25 \%$, and the soil corrosion capacity is increased due to the moisture content in this range. 


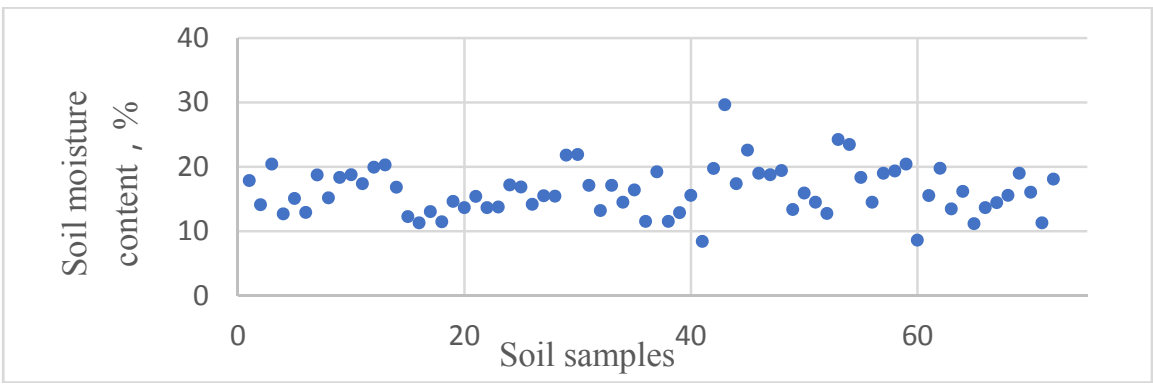

Fig. 2. Soil moisture distribution map of each station.

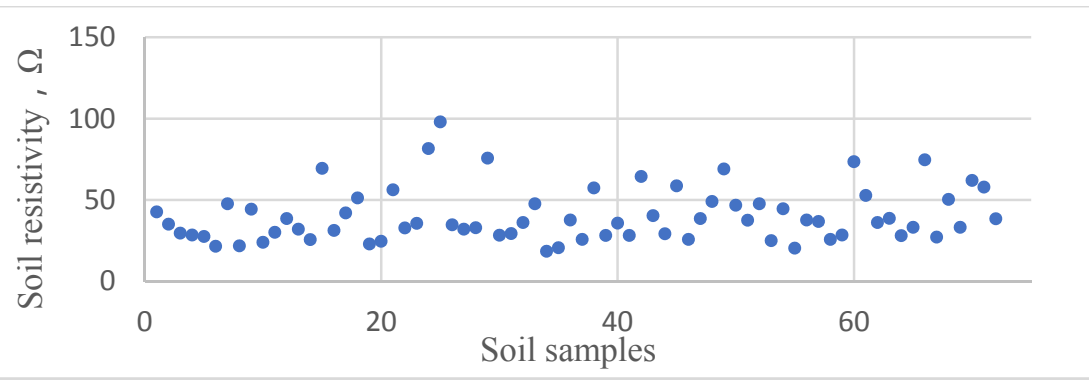

Fig. 3. Distribution of soil resistivity at each station.

\subsection{Soil resistivity}

For the common medium alkaline soil, the soil corrosivity increases with the decrease of resistivity. But for acid soil, the soil resistivity is high, and the corrosion is also serious. The soil resistivity of each station is shown in Figure 3. It can be seen that the soil resistivity of most stations is concentrated in $20-50 \Omega$ section.

\subsection{Soil $\mathrm{pH}$ value}

The $\mathrm{pH}$ test results of soil samples at each site are shown in Figure 4. It can be seen that the $\mathrm{pH}$ value of most sites is in the range of weak alkalinity to alkalinity. With the increase of soil $\mathrm{pH}$, the concentration of hydrogen peroxide in soil increases, and the depolarization of oxygen becomes the main cathodic reaction. When the depolarization of $\mathrm{O}_{2}$ becomes the control step, the cathodic reaction rate accelerates, the dissolution rate of anode metal accelerates, and the corrosion aggravates. The $\mathrm{pH}$ value of some stations is above 9 , and the soil corrosion ability is strong.

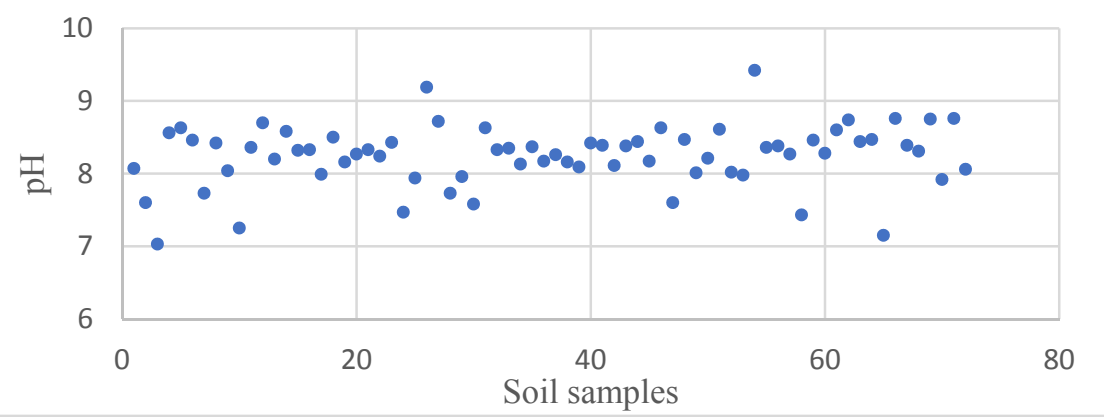

Fig. 4. Distribution of soil $\mathrm{pH}$ value at each station. 
Using the three-index evaluation system, the data and map are combined to get the results shown in Figure 5. Most of the sites are in the third grade of soil corrosion, which has a certain correlation with the industrial distribution of local cities. The sampling sites are located in the industrial concentration area, and the soil corrosivity is strong. In coastal areas, the corrosion is grade III, which is related to the soil moisture content and strong alkalinity.

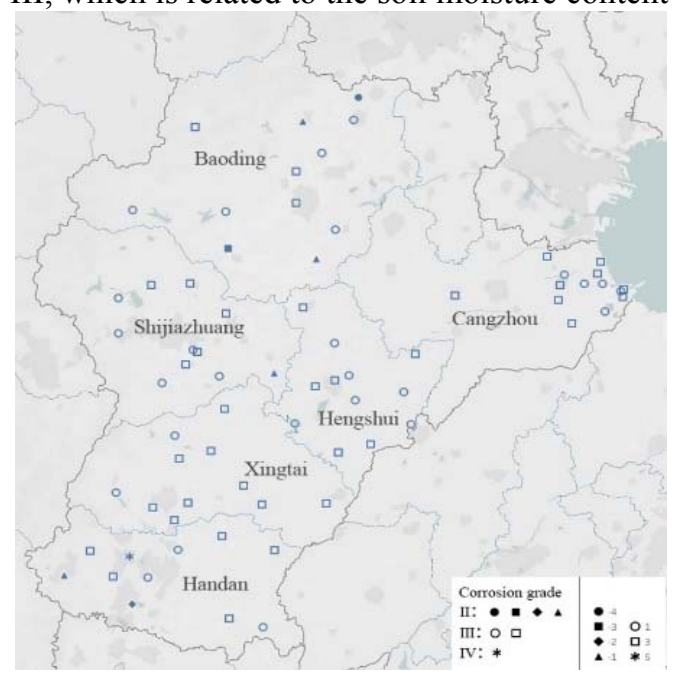

Fig. 5. Corrosion grade map.

\section{Conclusion}

There are many factors affecting the soil corrosion rate. This paper focuses on soil moisture content, soil resistivity and soil $\mathrm{pH}$ value. Based on the analysis of 72 soil samples from five cities in Southern Hebei Province, it is found that the soil corrosion in this area is characterized by "mild in the north and severe in the South". From the local point of view, the area with more serious soil corrosion is related to the concentration of heavy industry around the sampling point. The grade of soil corrosion in coastal areas is grade III. Soil water content and soil alkalinity play an important role in it. For the substation located in the area with high soil corrosion rate, the protection of grounding grid should be strengthened.

\section{References}

1. GB7172-1987 Method for the determination of soil water content

2. NY/T 121.2-2006 Soil Testing Part2: Method for determination soil $\mathrm{pH}$.

3. Jiao Chen, Zhaoqiong Chen, Yingwei Ai, Jingyao Xiao, Dandan Pan, Wei Li, Zhiyu Huang, Yumei Wang. "Impact of Soil Composition and Electrochemistry on Corrosion of Rock-cut Slope Nets along Railway Lines in China", Scientific Reports, 2015

4. Bhattarai, J., D. Paudal, and K. P. Dahal. "study on the soil corrosivity towards the buried-metallic pipes in Kathmandu and Chitwan valley of nepal." Asia Pacific Corrosion Control Conference (2016)

5. Saupi S R A, Sulaiman M A, Masri M N. Effects of Soil Properties to Corrosion of Underground Pipelines: A Review[J]. J. Trop. Resour. Sustain. Sci, 2015, 3: 14-18. 
6. El-Shamy A M, Shehata M F, Ismail A I M. Effect of moisture contents of bentonitic clay on the corrosion behavior of steel pipelines[J]. Applied Clay Science, 2015, 114: 461-466.

7. Rim-rukeh, Akpofure and Awatefe, J. Kehinde Investigation of Soil Corrosivity in the Corrosion of Low Carbon Steel Pipe in Soil Environment. Journal of Applied Science Research[J].2006,2(8):466-469.

8. Fu J, Pei F, Zhu Z, et al. Influence of moisture on corrosion behaviour of steel ground rods in mildly decertified soil[J]. Anti-Corrosion Methods and Materials, 2013, 60(3): 148-152.

9. Yoon G, Oh M, Park J. Laboratory study of landfill leachate effect on resistivity in unsaturated soil using cone penetrometer[J]. Environmental Geology, 2002, 43(1-2): 1828. 